\title{
PENGARUH KOMBINASI TERAPI WALKING EXERCISE DAN TERAPI MUSIK KLASIK TERHADAP FATIGUE PADA PASIEN KANKER PAYUDARA
}

\section{The Effect of Combination of Walking Exercise Therapy and Classical Music Therapy on Fatigue in Breast Cancer Patients}

\section{Anna Rufaida*, Esti Yunitasari, Ilya Krisnana 2}

1. Department Medical-Surgical Nursing, Faculty of Nursing, Universitas Airlangga, Surabaya

2. Department of Maternity and Child Nursing, Faculty of Nursing, Universitas Airlangga, Surabaya

\section{Riwayat artikel}

Diajukan: 2 Agustus 2019

Diterima: 28 Maret 2020

\section{Penulis Korespondensi: \\ - Anna Rufaida \\ - Universitas Airlangga \\ Surabaya \\ anna.rufaida- \\ 2017@fkp.unair.ac.id}

\section{Kata Kunci:}

walking exercise, musik, fatigue, exercise, musik klasik, Mozart

\begin{abstract}
Abstrak
Pendahuluan: Fatigue merupakan perasaan subjektif atas kelelahan fisik, kognitif, emosional berkaitan dengan kanker atau pengobatan kanker dan kelelahan yang dirasakan tidak sebanding dengan aktifitas yang dilakukan. Efek samping yang terjadi dapat menggangu pada sebelum pengobotan, saat atau setelah pengobatan. Walking exercise, telah diakui sebagai salah satu intervensi paling efektif untuk mengurangi kelelahan terkait kanker, sehingga pengobatan non farmakologi ini bisa menjadi sebuah alternative pilihan yang bisa dilakukan. Terapi musik juga dapat memberikan efek positif pada pasien dengan kanker payudara. Tujuan penelitian ini adalah menganalisis pengaruh kombinasi walking exercise dan terapi musik klasik terhadap fatigue pada pasien kanker payudara.

Metode: penelitian ini merupakan penelitian quasi experimental. Sampel penelitian adalah pasien kanker payudara yang melakukan kunjungan di puskesmas Surabaya yang memenuhi kriterian inklusi dan eksklusi dengan simple random sampling $(\mathrm{n}=48)$. Variabel independen dalam penelitian ini adalah kombinasi walking exercise dan mendengarkan musik klasik. Variabel dependen adalah fatigue. Pemberian intervensi kombinasi walking exercise dan mendengarkan musik klasik melalui media modul dan mp3. Pengukuran fatigue dengan menggunakan BFI (Brief Fatigue Inventory). Intervensi diberikan selama 3 minggu dan dilakukan 3 kali pengukuran (pre test dan post test). Uji analisis statistik menggunakan wilcoxone signed rank test
\end{abstract}

Hasil: Pada kelompok perlakuan ada perbedaan nilai fatigue sebelum dan sesudah 4 minggu intervensi kombinasi walking exercise dan musik klasik ada perbedaan yang bermakna fatigue sebelum dan sesudah 4 minggu latihan walking exercise dan musik klasik dengan nilai sig $<0,05$. Pada kelompok kontrol hasil uji wilcoxone signed rank test menunjukkan tidak ada pebedaan yang bermakna fatigue sebelum dan sesudah minggu ke 4 evaluasi dengan nilai 0,04 .

Kesimpulan: Kombinasi walking exercise dan mendengarkan musik klasik dapat menurunkan fatigue pasa pasien kanker payudara.

\section{Abstract}

Background: Fatigue is a subjective feeling of physical, cognitive, emotional fatigue related to cancer or cancer treatment and fatigue that is felt to be not comparable to the activities carried out. Side effects that occur can interfere with before weighting, during or after treatment. Walking exercise, has been recognized as one of the most effective interventions to reduce cancer-related fatigue, so this non-pharmacological treatment can be an alternative option that can be done. Music therapy can also have a positive effect on patients with breast cancer. The purpose of this study was to analyze the effect of a combination of walking exercise and classical music therapy on fatigue in breast cancer patients. 


\begin{abstract}
Method: this study is a quasi experimental study. The study sample was breast cancer patients who visited Surabaya health centers who met the criteria of inclusion and exclusion by simple random sampling $(n=48)$. The independent variable in this study was a combination of walking exercise and listening to classical music. The dependent variable is fatigue. Giving intervention combination of walking exercise and listening to classical music through module media and mp3. Measurement of fatigue using BFI (Brief Fatigue Inventory). The intervention was given for 3 weeks and carried out 3 measurements (pre test and post test). Test of statistical analysis using Wilcoxone signed rank test

Results: In the treatment group there were differences in the value of fatigue before and after 4 weeks of interventions with combination walking and classical music. There were differences in fatigue before and after 4 weeks of walking exercise and classical music with sig values $<0.05$. In the control group the results of the Wilcoxone signed rank test showed no significant differences in fatigue before and after the 4th week of evaluation with a value of 0.04 .

Conclusion: Combination of walking exercise and listening to classical music can reduce fatigue in breast cancer patients.
\end{abstract}

\section{PENDAHULUAN}

Kanker payudara merupakan kanker yang sering terjadi pada wanita dan menjadi salah satu penyebab kematian di dunia. Kanker payudara merupakan masalah kesehatan, baik di negara maju maupun negara berkembang. Menurut World Health Organization (WHO) tahun 2014, kanker payudara merupakan penyebab kematian nomor 2 (dua) setelah kanker serviks (Depkes,2015).

Data yang didapatkan berdasarkan jenis kanker pada tahun 2014-2017 adalah 1.409 penderita. Kasus kanker terbesar adalah kanker payudara seebesar 772 penderita, kanker serviks sebesar 218 penerita dan kanker ovarium sebesar 93 penderita (Dinkes, 2017). Kanker payudara memerlukan modalitas pengobatan untuk tujuan yang dapat dicapai sebagai penyembuhan, menghambat pertumbuhan sel-sel kanker, atau hanya menghilangkan gejala yang ditimbulkan oleh proses penyakit kanker (1). Pemberian kemoterapi dapat merubah irama sirkadian pasien (2),(3). Irama sirkadian adalah regulasi proses internal tubuh yang diatur oleh jam biologis tubuh, salah satunya adalah siklus tidur bangun (2). Pasien kanker selama kemoterapi mengalami ganguan irama sirkadian yang berkaitan dengan gangguan tidur dan sering terbangun26. Beberapa gangguan tidur selama kemoterapi adalah seringnya terbangun malam (49\% - 56 \%), ketidakmampuan untuk tidur dalam waktu 30 menit $(50 \%-73 \%)$ dan terbangun awal (49\% - $65 \%$ ) (4). Perubahan siklus tidur bangun yang dirasakan pasien selama pemberian kemoterapi dapat menyebabkan keluhan fatigue (5),(6). Fatigue merupakan perasaan subjektif atas kelelahan fisik, kognitif, emosional berkaitan dengan kanker atau pengobatan kanker dan kelelahan yang dirasakan tidak sebanding dengan aktifitas yang dilakukan (7). Efek samping yang terjadi dapat menggangu pada sebelum pengobotan, saat atau setelah pengobatan (8).

Keluhan fatigue yang di rasakan mengakibatkan kurangnya adaptasi pasien terhadap gangguan yang terjadi. Menurut teori konservasi yang disampaikan Myra Estrin Levine mengatakan bahwa untuk mempertahankan integritas dan meningkatkan adaptasi terhadap gangguan yang terjadi harus mempertahankan empat prinsip konservasi yaitu konservasi energi, konservasi integritas struktur, konservasi integritas personal dan konservasi integritas social. Salah satu konservasi yang dapat mengurangi fatigue dengan konservasi energi. Intervensi yang dapat dilakukan 
adalah dengan walking exercise dan musik klasik.

Walking exercise, telah diakui sebagai salah satu intervensi paling efektif untuk mengurangi kelelahan terkait kanker, sehingga pengobatan non farmakologi ini bisa menjadi sebuah alternative pilihan yang bisa dilakukan (1)

Terapi musik juga dapat memberikan efek positif pada pasien dengan kanker payudara. Musik dapat menurunkan aktivitas sistem saraf simpatik serta kecemasan, denyut jantung, laju pernafasan, dan tekanan darah yang berkontribusi pada perbaikan kualitas tidur yang secara langsung dapat menurunkan fatigue (9).

Penelitian ini bertujuan Menganalisis pengaruh kombinasi walking exercise dan musik klasik terhadap fatigue pada pasien kanker payudara.

\section{METODE}

Jenis penelitian ini adalah quasi experimental dengan rancangan penelitian pretest - postest control group design yang dilakukan di Puskesmas Pacarkeling, puskesmas kalijudan dan puskesmas rangkah pada bulan Juli 2019. Populasi dalam penelitian ini adalah pasien dengan kanker payudara. Sampel dalam penelitian ini diambil dari populasi dengan kriteria inklusi dan eksklusi, yaitu :

1. Kriteria Inklusi

1) Klien dengan kanker payudara stadium IIa-IIIb

2) Kilen dengan post kemoterapi dan post radioterapi

3) Kilen yang mengalami fatigue yang didapatkan setelah skrining menggunakan kuesioner BFI

4) Mampu diajak komunikasi

5) Kondisi pasien dalam keadaan baik dan stabil

6) Hb dan vital sign dalam batas normal

7) Klien dapat bejalan

8) Klien dengan pendamping/keluarga

2. Kriteria Eksklusi

1) Kilen mengalami gangguan pendengaran

2) Klien dengan anemia
3) Klien kanker payudara dengan metastase

3. Kriteria drop out

1) Bila subjek penelitian tidak melakukan latihan 3 kali berturutturut dari jumlah keseluruhan latihan yang dapat dilihat dari cek list yang sudah disediakan.

2) Mengundurkan diri dari penelitian

Besar sampel ditentukan berdasarkan estimasi untuk menguji hipotesis yang diperlukan sesuai dengan design yang telah ditentukan dihitung berdasarkan rumus uji hipotesis beda proporsi dua kelompok data berpasangan (10). Besar sampel dalam penelitian ini adalah 48 (masing-masing kelompok 24). Sampel diambil menggunakan simple random sampling. Pengukuran fatigue menggunakan kuesioner Brief Fatigue Inventory (BFI).

Setelah mendapatkan izin pengambilan data, peneliti melakukan pendataan pada populasi kanker payudara di puskesmas pacarkeling, puskesmas rangkah dan puskesmas kalijudan dalam 3 minggu di bulan juli 2019. Pada kelompok perlakuan dan kelompok kontrol dilakukan teknik matching untuk meminimalkan bias. Setelah mendapatkan responden terpilih pada kelompok perlakuan, peneliti menghubungi responden melalui telepon dengan tujuan mengkonfirmasi jadwal kunjungan yang akan dilakukan dirumah. Responden yang telah dipastikan diagnosis kanker payudara diberikan informed consent oleh peneliti. Apabila calon responden setuju dilanjutkan dengan pengisian lembar karakteristik responden. Peneliti meminta kesediaan responden untuk didatangi kerumah responden.

Pada pengukuran pre test fatigue, peneliti memberikan lembar kuesioner Brief Fatigue Inventory (BFI) yang akan diisi oleh responden. Kemudian peneliti melakukan pelatihan tentang kombinasi teknik walking exercise dan musik klasik dengan menggunakan media modul dan MP3 yang terdapat musik klasik. Peneliti juga mengajarkan cara menilai batas 
toleransi latihan yaitu $60-80 \%$ denyut jantung maksimal. Penghitungan denyut jantung maksimal dengan menggunakan rumus 220-usia. Penilaian batas toleransi dilakukan setiap 6 menit sekali selama latihan.

Peneliti melakukan evaluasi kemampuan responden dalam melakukan latihan yang akan dilakukan dalam penelitian. Peneliti juga memberikan modul serta MP3 yang terdapat musik klasik didalamnya sebagai acuan dalam melakukan latihan secara mandiri di rumah. Semua latihan dilakukan saat responden dalam kondisi stabil. Latihan yang meliputi walking exercise dilakukan selama 5 menit pendinginan, 12 menit berjalan dan 5 menit pemanasan, sehingga total latihan 22 menit. Latihan dilakukan 3x/minggu selama 3 minggu. Peneliti akan melakukan jadwal kunjungan tiap 3x/minggu untuk mengevaluasi ketepatan latihan yang sedang dilakukan dan perkembangan kondisi pasien. Pada tiap kali kunjungan peneliti melakukan pengukuran fatigue. Peneliti menganjurkan responden mengisi format checklist latihan sesuai jadwal latihan. Peneliti akan mengingatkan responden baik melalui telepon, sms, maupun media sosial untuk melakukan latihan secara mandiri sesuai arahan peneliti. Peneliti juga akan melibatkan keluarga responden dalam mengingatkan responden untuk melakukan latihan.
Peneliti melakukan kunjungan rumah untuk melakukan pengukuran fatigue dan memastikan responden pada kelompok kontrol tidak melakukan latihan apapun. Setelah dilakukan pengukuran pada minggu ke 3, peneliti akan mengajarkan latihan, membagikan modul dan MP3 sebagai acuan kepada kelompok kontrol.

Uji hipotesis yang digunakan untuk mengetahui perbedaan post test dan pre test antar kelompok intervensi dan kelompok control menggunakan wilcoxone signed rank test dengan nilai signifikasi $\mathrm{p}<0,05$.

\section{HASIL}

Puskesmas Pacarkeling sebagai kelompok perlakuan dan puskesmas kalijudan dan puskesmas rangkah kota Surabaya sebagai kelompok kontrol dipilih melalui random. Subyek penelitian adalah pasien kanker payudara yang terdata pada tiga puskesmas kota Surabaya yang memenuhi kriteria penelitian sebanyak 48 responden (masingmasing kelompok 24 responden).

Hasil uji wilcoxone signed rank test berdasarkan hasil di atas pada data BFI diketahui bahwa nilai signifikansi semua variabel $<0,05$. Sehingga dapat dikatakan bahwa ada perbedaan yang signifikan antara pretes - posttest BFI pada perlakuan kombinasi Walking Exercise dan Musik Klasik.

Tabel 1. Demografis dan karakteristik peserta $(n=48)$

\begin{tabular}{|c|c|c|c|c|c|c|}
\hline \multirow[t]{2}{*}{ No } & \multirow{2}{*}{ Karakteristik } & \multicolumn{2}{|c|}{ Kelompok Intervensi } & \multicolumn{2}{|c|}{ Kelompok Kontrol } & \multirow[t]{2}{*}{ Mean \pm SD } \\
\hline & & $\mathrm{F}$ & $\%$ & $\mathrm{~F}$ & $\%$ & \\
\hline \multirow[t]{5}{*}{1.} & Usia (tahun) & & & & & \\
\hline & Usia 37-42 & 6 & 25.0 & 5 & 20.8 & $\begin{array}{c}\mathrm{P}=1,453 \pm \\
2,517\end{array}$ \\
\hline & Usia 43-48 & 8 & 33.3 & 8 & 33.3 & $\begin{array}{c}\mathrm{K}=1,732 \pm \\
3,000\end{array}$ \\
\hline & Usia 49-55 & 11 & 45.8 & 11 & 45.8 & \\
\hline & 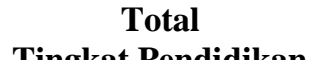 & 24 & 100 & 24 & 100 & \\
\hline \multirow[t]{4}{*}{2.} & $\begin{array}{l}\text { Tingkat Pendidikan } \\
\text { SMP }\end{array}$ & 9 & 37.5 & 7 & 29.2 & \\
\hline & SMA & 12 & 50.0 & 15 & 62.5 & \\
\hline & Perguruan Tinggi & 3 & 12.5 & 2 & 8.3 & \\
\hline & Total & 24 & 100 & 24 & 100 & \\
\hline \multirow[t]{2}{*}{3.} & Pekerjaan & & & & & \\
\hline & IRT & 18 & 75.0 & 18 & 75.0 & \\
\hline
\end{tabular}




\begin{tabular}{ccccc}
\hline Pegawai swasta & 3 & 12.5 & 4 & 16.7 \\
Wiraswasta/pedagang & 3 & 12.5 & 2 & 8.3 \\
Total & 24 & 100 & 24 & 100 \\
\hline
\end{tabular}

Tabel 2. Pre test dan post test fatigue kelompok perlakuan dan kontrol $(n=48)$

\begin{tabular}{lrr}
\hline & $\begin{array}{l}\text { Posttest_BFI_Perlakuan - } \\
\text { Pretest_BFI_Perlakuan }\end{array}$ & $\begin{array}{l}\text { Posttest_BFI_Kontrol - } \\
\text { Pretest_BFI_Kontrol }\end{array}$ \\
\hline Z & $-4.373 \mathrm{~b}$ & $-2.919 \mathrm{~b}$ \\
Asymp. Sig. (2-tailed) & .000 & .004 \\
\hline
\end{tabular}

\section{PEMBAHASAN}

Hasil penelitian menunjukkan bahwa kombinasi latihan walking exercise dan musik klasik mempengaruhi penurunan fatigue. Pada kelompok perlakuan hasil uji Hasil uji wilcoxone signed rank test menunjukkan ada perbedaan yang bermakna fatigue sebelum dan sesudah 4 minggu latihan walking exercise dan musik klasik dengan nilai sig $<0,05$. Pada kelompok kontrol hasil uji wilcoxone signed rank test menunjukkan tidak ada pebedaan yang bermakna fatigue sebelum dan sesudah minggu ke 4 evaluasi dengan nilai 0,04 .

Penelitian dari (11) yang menyatakan bahwa terapi musik ini sudah diakui sebagai intervensi yang dapat dilakukan untuk pasien kanker, karena musik dapat memberikan manfaat bagi pasien karena dapat mengalihkan perhatian mereka dari pengalaman yang tidak menyenangkan dan intervensi yang dilkukan selanjutnya.

Penelitian ini semakin diperkuat oleh penelitian dari (12) yang menyatakan bahwa latihan walking excercise ini dilakukan selama 12 menit melakukan walking dan 10 menit untuk pemanasan dan pendinginan. Latihan ini dilakukan minimal 3 sampai 4 kali seminggu. Latihan ini dapat memberikan efek positif bagi pasien dengan kanker payudara yang menjalani pengobatan kemoterapi. Penelitian dari (Chen, Tsai et al, 2016) juga mengatakan bahwa walking exercise dapat menunjukkan korelasi yang kuat antara aktivitas fisik, kualitas tidur, dan ritme aktivitas istirahat. Dengan demikian, olahraga dapat menstabilkan aktivitas istirahat irama dan meningkatkan kualitas tidur yang secara langsung dapat menurunkan fatigue.

Dari hasil penelitian ini peneliti berasumsi bahwa fatigue pada kelompok kontrol yang tidak dilakukan intervensi hasil pretest-post test rerata penurunan fatigue pertama terbilang lama. Sedangkan pada responden kelompok intervensi hasil rerata pretest responden yang masih rendah dan setelah diberikan tindakan walking exercise dan musik klasik, didapatkan hasil rerata post test responden mengalami penurunan fatigue dan gangguan tidur yang signifikan.

\section{KESIMPULAN}

Hasil penelitian ini menunjukkan ada pengaruh yang signifikan kombinas latihan walking excecise dan musik klasik terhadap penurunan fatigue.

\section{KONFLIK KEPENTINGAN}

Tidak ada

\section{SUMBER PENDANAAN}

Penelitian ini adalah proyek penelitian yang didanai sendiri

\section{IJIN ETIK}

Protokol penelitian telah disetujui oleh Komite Etik Penelitian Kesehatan (KEPK) dengan Nomor : 1577-KEPK dan oleh Komisi Etik Penelitian Kesehatan Fakultas 
Keperawatan Universitas Airlangga

Surabaya.

\section{DAFTAR PUSTAKA}

Qi Zhang. International Journal of Nursing Studies E ff ects of nurse-led homebased exercise \& cognitive behavioral therapy on reducing cancer-related fatigue in patients with ovarian cancer during and after chemotherapy: A randomized controlled trial. Int $\mathbf{J}$ Nurs Stud [Internet]. 2018;78(August 2017):52-60. Available from: https://doi.org/10.1016/j.ijnurstu.201 7.08.010

Liu L, Rissling M, Neikrug A, Faierman M, Mills PJ, Parker BA, et al. Fatigue: Biomedicine, Health \& Behavior Fatigue and circadian activity rhythms in breast cancer patients before and after chemotherapy: a controlled study. 2013;(October):3741.

Ryan JL, Carroll JK, Ryan EP, Mustian KM, Fiscella K, Morrow R. Mechanisms of Cancer-Related Fatigue. 2007;12(suppl 1):22-34.

Peppone L, Innominato PF, Janelsins M, Jeong M, Sprod L, Savard J, et al. Prevalence, putative mechanisms, and current management of sleep problems during chemotherapy for cancer. 2012;151-63.

Payne JK. Altered Circadian Rhythms and
Cancer- Related Fatigue Outcomes. 2011;

Wang XS. Pathophysiology of CancerRelated Fatigue. 2008;12(5):109286.

Taukhid M. Issn : 2579-7301. 2017;5(2):29-37.

Carolina et al. Randomized Evaluation of Cognitive-Behavioral Therapy and Graded Exercise Therapy for PostCancer Fatigue. J Pain Symptom Manage. 2017;54(1):74-84.

Wang. International Journal of Nursing Studies Music therapy improves sleep quality in acute and chronic sleep disorders: A meta-analysis of 10 randomized studies. Int $\mathbf{J}$ Nurs Stud. 2014;51(1):51-62.

Dahlan MS. Besar sampel untuk desain khusus. Dalam Aklia S, penyunting Besar sampel dan cara pengambilan sampel dalam Penelit Kedokt dan kesehatan Seri Evid based Med. 2013;2:81-115.

Pauwels EKJ, Mariani G. Mozart, Music and Medicine. 2014;403-12.

Anna L. Schwartz. breast cancer receiving chemotherapy. 2001; (August 2000):718-23.

Chen H, Tsai C, Wu Y, Lin K, Lin C. Effect of walking on circadian rhythms and sleep quality of patients with lung cancer : a randomised controlled trial. 2016;115(11):1304-12. Available from:

http://dx.doi.org/10.1038/bjc.2016.3 56 